Open Access

\title{
Frequency of coreceptor tropism in PBMC samples from HIV-1 recently infected blood donors by massively parallel sequencing: the REDS II study
}

\author{
Rodrigo Pessôa ${ }^{1}$, Ester C Sabino ${ }^{2}$ and Sabri S Sanabani ${ }^{1,3^{*}}$ (D)
}

\begin{abstract}
Background: The interaction of HIV-1 and target cells involves sequential binding of the viral gp120 Env protein to the CD4 receptor and a chemokine co-receptor (either CCR5 or CXCR4). CCR5 antagonists have proved to be an effective salvage therapy in patients with CCR5 using variants (R5) but not with variants capable of using CXCR4 ( $\times 4)$ phenotype. Thus, it is critically important to determine cellular tropism of a country's circulating HIV strains to guide a management decision to improve treatment outcome. In this study, we report the prevalence of R5 and $\times 4$ HIV strains in 45 proviral DNA massively parallel sequencing "MPS" data from recently infected Brazilian blood donors.
\end{abstract}

Methods: The MPS data encompassing the tropism-related V3 loop region of the HIV-1 env gene was extracted from our recently published HIV-1 genomes sequenced by a paired-end protocol (Illumina). HIV-1 tropism was inferred using Geno2pheno [coreceptor] algorithm (3.5\% false-positive rate). V3 net charge and 11/25 rules were also used for coreceptor prediction.

Results: Among the 45 samples for which tropism were determined, 39 were exclusively R5 variants, $5 \times 4$ variants, and one dual-tropic or mixed (D/M) populations of R5 and $\times 4$ viruses, corresponding to $86.7,11.1$ and $2.2 \%$, respectively. Thus, the proportion of all blood donors that harbor CXCR4-using virus was $13.3 \%$ including individuals with D/M-tropic viruses.

Conclusions: The presence of CCR5-tropic variants in more than $85 \%$ of our cohort of antiretroviral-naïve blood donors with recent HIV-1 infection indicates a potential benefit of CCR5 antagonists as a therapeutic option in Brazil. Therefore, determination of viral co-receptor tropism is an important diagnostic prerequisite.

\section{Background}

The interaction of human immunodeficiency virus type 1(HIV-1) and target cells involves sequential binding of the viral gp120 Env protein to the CD4 receptor and a chemokine co-receptor [1]. The high selection pressures exerted on the viral gp120 molecule explain why the HIV-1 viral populations have very high genetic diversity.

\footnotetext{
* Correspondence: sabyem_63@yahoo.com

'Department of Pathology, Hospital das Clínicas, School of Medicine, University of São Paulo, São Paulo, Brazil

${ }^{3}$ Medicina Instituto de Medicina Tropical de São Paulo, LIM 52 - Av. Dr. Enéas Carvalho de Aguiar, 470 - $2^{\circ}$ andar - Cerqueira Cesar, 05403-000 Sao Paulo, SP, Brazil

Full list of author information is available at the end of the article
}

Early after infection, HIV-1 variants are largely or exclusively bind to $\beta$-chemokine co-receptor CCR 5 in conjunction with CD4 molecules; such variants are termed 'R5 viruses' [2]. These viruses are non-syncytiuminducing isolates and do not replicate in T-cell lines, but replicate well in macrophages and are known as macrophage tropic strains. T-cell line-tropic HIV-1 viruses using another $\alpha$-chemokine receptor, CXCR4, called $\times 4$. variants while dual tropic or mixed $(\mathrm{D} / \mathrm{M})$ populations can interact with both CCR5 and CXCR4 coreceptors in the fusion process [3]. The emergence of $\times 4$ viruses and $\mathrm{D} / \mathrm{M}$ isolates generally occur at the later stage of infection and are consistently associated with increased severity of disease in roughly half of all persons infected with 
HIV [4-6]. Currently, there is much interest in determining coreceptor tropism before initiating treatment with the CCR5 coreceptor blocker maraviroc which has exclusive activity against R5 viruses [7, 8]. HIV-1 tropism may be determined by phenotypic or genotypic assays. Phenotypic testing assess the ability of pseudoviruses carrying the entire cloned env gene from a patient's virus to infect CCR5 or CXCR4 reporter cell-lines that also express CD4 molecules [9]. Although this approach has demonstrated good sensitivity and correlates well with clinical outcome [7], phenotypic testing are complex to perform, prohibitively expensive, and time-consuming. It may also be inferred genotypically from the 35-aminoacid V3 loop region of the viral envelope protein, gp120 sequence [10]. Emerging data from several studies indicate that genotypic approach has several advantages over the phenotypic assay that include a low cost, simpler technical demands, faster turnaround time, and more suitable to a large series compared with phenotypic tropism testing $[11,12]$. Moreover, genotypic predictors proved to be highly concordant with phenotype data and can reliably be used to determine viral tropism particularly in treatment-experienced patients $[8,12,13]$. Previous studies generally indicated that CXCR4-using viruses carry positively charged amino acids in the V3 loop, while CCR5tropic viruses do not $[14,15]$. In a clinical setting, detection of $\times 4$ variants at low concentrations is considered important because they may potentially emerge during therapy with a CCR5 antagonist. To improve the laboratory detection sensitivity of $\times 4$ minority species in aviremic patients, the European Consensus Group guidelines recommended generation of sequences through independent triplicate PCR amplification and/or by deep sequencing technology $[12,16]$.

Despite the fact that Maraviroc has been used in Brazil since 2007, few data are available about its efficacy during routine use. Recently, Alencar et al. [17] found that $27.5 \%$ of samples from patients failing previous antiretroviral therapy harbored one or more mutations that confer some degree of susceptibility to maraviroc. In another study, Araújo and coworkers [18] reported that most of the resistance-associated mutations in ARV-naïve patients occur in subtype $\mathrm{C}$ compared with subtype $\mathrm{B}$ strains.

Here, we report the prevalence of $R 5, \times 4$, and $D / M$ variants of HIV-1 from massively parallel sequencing "MPS" proviral data generated during the early phase of HIV-1 infection in a group of first-time Brazilian blood donors. Although plasma HIV-1 RNA has been widely used to determine the viral tropism the proviral PBMC DNA sequence can contain a variety of multiple archived genomes that are not present in plasma. This, combined with the stability of DNA compared with RNA, and the fact that HIV DNA recovered from the proviral compartment can reliably be used as an alternative to RNA tropism testing
[19-22] influenced our decision to use proviral DNA in this study.

\section{Methods}

Previously, we had described the genetic diversity of HIV-1 using partial $(n=6)$ and near full-length genomes (NFLG) sequence $(n=39)$ of human immunodeficiency virus Type 1 provirus deep sequencing data from recently infected donors at four blood centers participating in the Retrovirus Epidemiology Donor Study (REDS-II) International Program in Brazil [23]. Samples were classified by less-sensitive (LS) or "detuned" enzyme immunoassay (Vironostika HIV-1 MicroElisa; bioMérieux, Durham, NC) or an LS chemiluminescent immunoassay (Vitros HIV-1/2 Assay; Ortho Diagnostics, Rochester, NY) as recently infected at the time of donation based on antibody levels consistent with recent seroconversion (infected for $<170$ days) as previously described [24]. None of the participants received antiviral treatment before. All study subjects provided written informed consent. The study was approved by the local ethical review committee of participating institutions as well as the REDS-II collaborating centers (Blood Systems Research Institute/University of California at San Francisco, San Francisco, CA) and data coordinating center (Westat, Inc.) in the United States.

\section{Extraction of reads spanning the V3 region from HIV MPS}

In this study, a sub-library of the env V3 population sequence derived from each sample was created by mapping the raw MPS short reads to their corresponding V3 consensus sequence (Sequences positions: 210 to 315 [GenBank accession no. K03455] in standard reference HXB2) using the CLC Genomics Workbench version 7.0.4 (CLC Bio, Aarhus, Denmark). To avoid artificial generation of in silico chimeras through assembly and to evade inflating the diversity estimates of the V3 region, the analysis was restricted to individual paired-end reads that encompass the complete V3 region from each dataset. The reads were aligned, truncated and translated for genotyping. Prior to the determination of viral tropism, the MPS data were filtered out by the presence of frame shifts, stop codons, and base-call ambiguity.

\section{Determination of HIV-1 coreceptor tropism}

HIV-1 co-receptor tropism was assessed from the filtered V3 MPS data using the new prediction tool geno2phenoC_NGS-Sanger implemented in the Geno2Pheno [coreceptor] (http://coreceptor.bioinf.mpi-inf.mpg.de/), which uses support vector machine technology. To minimize the number of false predictions of CXCR4 tropic sequences as CCR5 tropic, tropism was inferred using cutoffs optimized and validated in the maraviroc treatment-experienced trials and A4001029 clinical trials $[16,25]$. Therefore, $\times 4$ or 
$\mathrm{D} / \mathrm{M}$ viruses (non-R5) were reported positive if their sequences had a prediction FPR result of $\leq 3.5 \%$ (3.5 \% probability of classifying an R5 virus falsely as $\times 4$ ) or the $11 / 25$ rule [26] predicted a $\times 4$ virus, otherwise, they were considered CCR5-tropic viruses. The detection threshold of minor $\times 4$ variants varied according to the number of extracted full-length reads of $\mathrm{V} 3$ for each sample. Moreover, the overall net charge (NC) of V3 amino acid $(R+K-D-E)$ were assigned to each sequence fragment to predict HIV-1 tropism [27, 28]. Sequences with $\mathrm{NC}$ values $<5.0$ were classified as $\mathrm{R} 5$, whereas sequences with $\mathrm{NC}$ values $\geq 5.0$ were classified as $\times 4$.

\section{Nucleotide distance analysis}

The intra-host viral genetic diversities of the V3 nucleotide sequences were computed from all available deep sequences in each clinical sample using the maximum composite likelihood in MEGA version 6 [29].

\section{Nucleotide sequence accession numbers}

The sequencing data have been uploaded to zenodo https://zenodo.org/ (DOI: 10.5281/zenodo.14666).

\section{Results}

The near full-length genomes and/or larger fragments of the 45 V3 MPS data used in this study have recently been described for their genetic variability [23]. This analysis indicated that 28 (62.2\%) were subtype B sequences, 11 (24.4\%) BF1 recombinants, 2 (4.4\%) BC recombinants, $1(2.2 \%)$ were $\mathrm{BC}$ and $\mathrm{BCF} 1$ each, 1 (2.2\%) CRF45_cpx, and 1 (2.2\%) were the newly described CRF70_BF1 [30]. The tropism predictions, FPR values, and V3 net charges are shown in Table 1. The datasets of the V3 sequence extracted from the NFLGs ranged from 7 sequences in patient 10BR_SP048 to 14026 sequences in patient 10BR_PE091. After removal of scaffolding reads not covering the complete V3 region, the coverage dropped from 282 to one read in subject 10BR_MG029. Overall, $68.9 \%$ of the samples showed a V3 loop region covered by more than 100 sequencing reads. All MPS reads from the 45 proviral samples in which a complete V3-loop sequence was found were submitted to the geno2pheno [coreceptor] prediction tool. This analysis revealed virus populations with a pure $\mathrm{R} 5$ and $\times 4$ phenotype in $39(86.7 \%)$ and 5 $(11.1 \%)$ blood donors, respectively. The presence of D/M-tropic sequences was found in one (2.1\%) subject. Thus, the proportion of all blood donors that harbor CXCR4-using virus was $13.2 \%$ including the donor with $\mathrm{D} / \mathrm{M}$-tropic viruses. According to the NC, $66.6 \%$ of sequences predicted as $\times 4$ by geno2pheno showed NC values $\geq 5$; similarly, $95 \%$ of sequences predicted as $\mathrm{R} 5$ by geno2pheno had NC values below 5 . Regarding the $\mathrm{D} / \mathrm{M}$ viruses, the $\mathrm{V} 3$ domains sequences displayed $\mathrm{NC}<5$.
The V3 consensus sequences from the 45 samples were aligned and investigated for the presences of the GWGR motif in the V3 loop, a feature commonly observed on the Brazilian B subtype samples (Fig. 1). The tetrapeptide GWGR $\backslash$ AWGR motif in the V3 loop apex sequence was observed in 5 (11.1\%) donors infected with pure subtype B and all had predicted R5 viruses. The aligned sequences were also analyzed for the presence of A316T and I323V resistance-conferring point mutations to maraviroc in $\mathrm{R} 5$ and $\mathrm{D} / \mathrm{M}$ viruses The A316T substitution was detected in 7 (17.9 \%) donors, whereas the I323V substitution was detected in only three $(7.7 \%)$ subjects; both mutations have been shown to confer maraviroc partial resistance [31]. Phenotypic assays are necessary to confirm the influence of this mutation to maraviroc susceptibility. Since maraviroc was used in Brazil after 2007 on therapy-failure patients, high rate in treatment-naïve samples may be related to the transmission of maraviroc-resistant variants from patients with treatment experience.

\section{Discussion}

In this study, we sought to estimate the prevalence of coreceptor tropism of the archived strains at the time of primary infection using a total of 45 MPS data from HIV-1 recently infected Brazilian first-time blood donors. We found $6 \times 4$ strains $(13.3 \%)$ including the $\mathrm{D} / \mathrm{M}$ tropic populations $(n=1)$ and 39 exclusive R5 variants $(86.7 \%)$. The prevalence found for $\times 4$ DNA was similar to that reported $16.4 \%-17.2 \%$ of $\times 4$ and D/M-tropic strains in recent HIV-1 seroconverter Spanish subjects $[32,33]$. These results were also comparable to those of Frange et al. [34] who reported a relatively high frequency $(15.9 \%)$ of $\times 4$ and $\mathrm{D} / \mathrm{M}$ virus in $390 \mathrm{HIV}-1$ subtype-B infected patients diagnosed at the time of primary infection. Our results were also consistent with those of a previous study in drug-naive chronically HIVinfected individuals $[35,36]$ and in suppressed patients with a shorter history of viremia suppression [37-39]. In contrast, our prevalence estimates of CXCR4-using viruses is higher than those found in 126 recently infected men having sex with men in the USA study of $3.2 \%$ [40] and less than the rate of prevalence reported in our previous study in recently infected Brazilian subjects (30.2 \%) [41]. Factors that might have contributed to the differences observed were the sample size, type of samples, the sequencing method, the test replications, the FPR cutoff, and prediction algorithms used.

The relatively high rate of CXCR4-using viruses in this study may be explained by the application of deep sequencing technology which has improved the prediction of HIV tropism as has been reported in previous studies $[16,42,43]$. Using our approach, we were able to detect one $\times 4$ variant that existed as a mixture along with $R 5$ 
Table 1 Genetic subtype, coreceptor usage, net charge and sequence coverage across V3 region in PBMC for the HIV-1 isolates

\begin{tabular}{|c|c|c|c|c|c|c|c|}
\hline Sample ID & $\begin{array}{l}\text { Subtype based } \\
\text { on NFLG }\end{array}$ & $\begin{array}{l}\text { geno2pheno } \\
\left(3.5 \% \mathrm{FPR}^{2}\right)\end{array}$ & $\begin{array}{l}\text { Coverage including } \\
\text { all short reads }\end{array}$ & $\begin{array}{l}\text { Overall mean } \\
\text { Div. } \%\end{array}$ & $\begin{array}{l}\text { Coverage of the } V 3 \\
\text { reads after filteration }\end{array}$ & $\begin{array}{l}\text { Subtype based on } \\
\text { the V3 sequence }\end{array}$ & $\begin{array}{l}\text { Number of seq. with } \\
\text { charges }<5 / \geq 5\end{array}$ \\
\hline 10BR_001PE & B & $\times 4$ & 322 & 1.1 & 132 & B & $06 / 126$ \\
\hline 10BR_003MG & BF1 & R5 & 9985 & 0.7 & 532 & F1 & $531 / 01$ \\
\hline 10BR_003SP & B & R5 & 876 & 1.4 & 296 & B & $270 / 26$ \\
\hline 10BR_007MG & B & R5 & 80 & 1.3 & 4 & B & $04 / 00$ \\
\hline 10BR_008SP & B & R5 & 655 & 0.7 & 120 & B & $119 / 1$ \\
\hline 10BR_009SP & B & R5 & 1031 & 1.0 & 290 & B & $271 / 19$ \\
\hline 10BR_010MG & BCF1 & R5 & 13756 & 1.0 & 763 & F1 & $736 / 27$ \\
\hline 10BR_010PE & B & R5 & 1103 & 0.8 & 345 & B & $330 / 15$ \\
\hline 10BR_011SP & CRF45_cpx & R5 & 24 & 0.8 & 10 & $\mathrm{~A} 1$ & $10 / 00$ \\
\hline 10BR_014SP & B & R5 & 404 & 0.7 & 176 & B & $174 / 02$ \\
\hline 10BR_015RJ & BF1 & R5 & 3687 & 1.4 & 818 & F1 & $813 / 05$ \\
\hline 10BR_017SP & BF1 & R5 & 494 & 0.4 & 8 & F1 & $08 / 00$ \\
\hline 10BR_017MG & BF1 & R5 & 31 & 0.7 & 108 & F1 & $108 / 00$ \\
\hline 10BR_018PE & $B C$ & R5 & 48 & 0.0 & 13 & B & $13 / 00$ \\
\hline 10BR_021SP & B & R5 & 838 & 1.0 & 289 & B & $288 / 01$ \\
\hline 10BR_023RJ & BF1 & $\mathrm{R} 5 / \times 4$ & 446 & 1.5 & 248 & F1 & $248 / 00$ \\
\hline 10BR_026RJ & BF1 & R5 & 3281 & 1.1 & 888 & B & $48 / 840$ \\
\hline 10BR_029MG & B & $\times 4$ & 282 & 0.0 & 1 & B & $00 / 01$ \\
\hline 10BR_029PE & BCF1 & $\times 4$ & 909 & 0.9 & 183 & F1 & 06/177 \\
\hline 10BR_032RJ & B & R5 & 1732 & 2.0 & 733 & B & 733/00 \\
\hline 10BR_034MG & BF1 & R5 & 844 & 0.7 & 51 & B & $51 / 00$ \\
\hline 10BR_034PE & B & R5 & 679 & 0.9 & 369 & B & $350 / 19$ \\
\hline 10BR_035MG & B & R5 & 851 & 1.2 & 469 & B & $462 / 07$ \\
\hline 10BR_038SP & B & R5 & 2247 & 1.8 & 352 & B & $338 / 15$ \\
\hline 10BR_041RJ & BF1 & R5 & 342 & 0.8 & 160 & $\mathrm{~F} 1$ & $147 / 13$ \\
\hline 10BR_042SP & B & R5 & 1269 & 2.0 & 293 & B & $279 / 14$ \\
\hline 10BR_043SP & B & $\times 4$ & 65 & 1.7 & 26 & B & $006 / 2020$ \\
\hline 10BR_045SP & B & R5 & 137 & 0.0 & 8 & B & $08 / 00$ \\
\hline 10BR_046RJ & CRF70_BF1 & R5 & 112 & 0.4 & 32 & B & $32 / 00$ \\
\hline 10BR_046SP & CF1 & R5 & 2830 & 2.0 & 278 & C & $273 / 5$ \\
\hline 10BR_048SP & BF1 & R5 & 7 & 0.0 & 5 & B & $05 / 00$ \\
\hline 10BR_049SP & B & R5 & 632 & 3.5 & 44 & B & $44 / 0$ \\
\hline 10BR_050RJ & B & R5 & 1695 & 2.5 & 341 & B & $335 / 06$ \\
\hline 10BR_050SP & B & R5 & 1067 & 2.2 & 47 & B & $35 / 12$ \\
\hline 10BR_051RJ & B & $\times 4$ & 4301 & 0.5 & 482 & B & $474 / 08$ \\
\hline 10BR_053PE & B & R5 & 2480 & 2.0 & 784 & B & $750 / 34$ \\
\hline 10BR_053RJ & BF1 & R5 & 3718 & 0.9 & 2011 & F1 & $1888 / 123$ \\
\hline 10BR_054RJ & B & R5 & 2173 & 0.9 & 745 & B & $655 / 90$ \\
\hline 10BR_055SP & B & R5 & 1393 & 1.5 & 59 & B & $59 / 00$ \\
\hline 10BR_056PE & B & R5 & 551 & 0.5 & 10 & B & $00 / 10$ \\
\hline 10BR_057SP & BF1 & R5 & 2704 & 0.6 & 1322 & F1 & $1319 / 3$ \\
\hline 10BR_091PE & B & R5 & 14026 & 0.8 & 2165 & B & $2161 / 4$ \\
\hline 10BR_097PE & B & R5 & 3773 & 3.3 & 697 & B & $675 / 22$ \\
\hline 10BR_098PE & B & R5 & 10215 & 5.3 & 1456 & B & $1311 / 145$ \\
\hline 10BR_100PE & B & R5 & 6060 & 3.7 & 614 & B & 613/01 \\
\hline
\end{tabular}




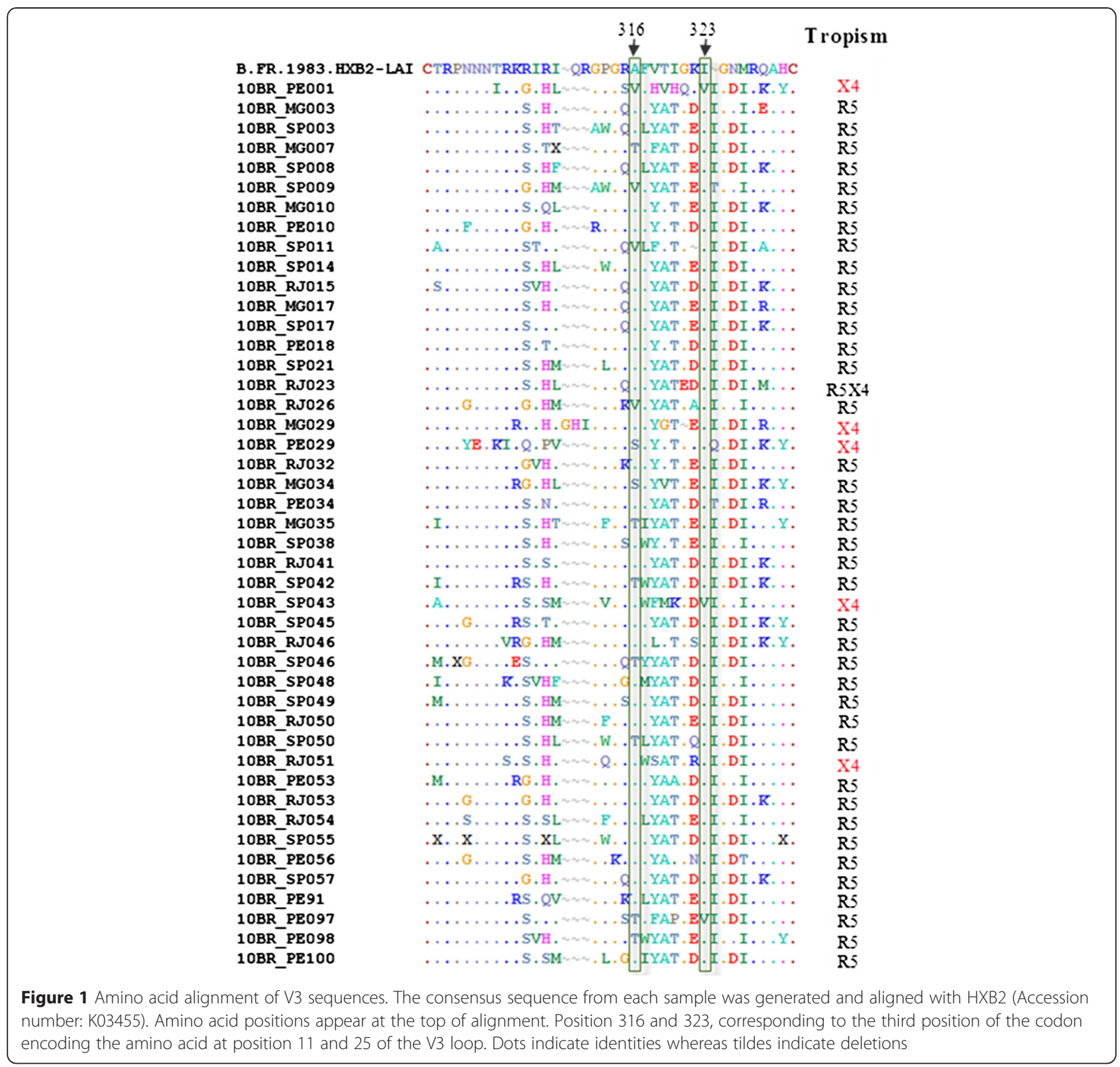

isolates in subject 10BR_023RJ. If standard populationbased sequencing data had been used alone, we would have not been able to detect the $\times 4$ variants in that subject as it presents in $3.2 \%$ of the viral population. The detection of dual or mixed $R 5 \times 4$ viral strains from sample collected at the earliest time point could be the result of concomitant transmission of multiple variants, or successive infections within a short timeframe. The assumption of direct transmission of the mixed variants in subject 10BR_023RJ do not support the hypothesis of gatekeeping event that almost always selects for transmission of R5 over $\times 4$ HIV-1 strains [44]. Indeed, there is no convincing evidence has yet been published to proof the lower transmissibility of $\times 4$ viruses but available data support the idea that $\mathrm{R} 5$ or $\mathrm{D} / \mathrm{M}$ infections could result from a stochastic process $[45,46]$.

This relatively high prevalence should seriously be considered when decisions are made about initial regimens for therapy-naive individuals, and HIV-1 coreceptor usage should be screened before initiation of any chemokine receptor CCR5 antagonists in clinical settings. These suggestions are in agreement with the conclusions of Frange et al. [34] that noted that $\times 4 / \mathrm{DM}$ strains can fuel the cellular $\mathrm{HIV}-1$ reservoir leading to viral persistence over a long period complicating future therapeutic options, including CCR5 antagonists.

One of the major limitations beside the small sample size of this study is that the assessment of HIV tropism 
was limited to sequence- based algorithms rather than using phenotypic methods. Although phenotypic assays still have an edge over genotypic methods, genotypic predictors prove to be highly concordant with phenotype data and can reliably be used to determine viral tropism with better results in PBMC than in plasma samples [47]. In this study, we used geno2pheno because it allows for an adjustable cutoff, and it can determine HIV1 co-receptor usage in all viral genotypes. This method has shown a similar performance to the Trofile phenotypic assay, the most often used tropism method [48]. Moreover, the method has been shown to achieve higher sensitivity while retaining high level of specificity when compared with the performance of different algorithms $[49,50]$. In some samples there were little or no sequencing coverage in the $\mathrm{V} 3$ region and this may have biased the results of this study.

\section{Conclusions}

Although the sample size is small and not representative, our findings add further support to the previous studies and show that $\times 4$ variants may be frequently found at a relatively high proportion in early infected subjects. More studies with large samples size are needed to replicate our findings and to explore the clinical relevance of the variants with predicted usage of CXCR4 present in the light of both clinical progression and therapeutic approach. In conclusion, while suggesting CCR5 antagonists (maraviroc) as useful therapeutic approach, it has to be noted as a caution, that maraviroc resistant R5 strains described in present study were isolated from non-treated, recently HIV-1 infected individuals.

\begin{abstract}
Abbreviations
HIV-1: Human immunodeficiency virus type 1; CXCR4: chemokine receptor type 4; CCR5: C-C chemokine receptor type 5; X4: CXCR4-using virus; R5: CCR5-using virus; D/M: Dual-mixed virus; FPR: False positive rate; MPS: massively parallel sequencing; PBMCs: Peripheral blood mononuclear cells; NC: Net charge.
\end{abstract}

\section{Competing interests}

The authors declare that they have no competing interests.

\section{Authors' contributions}

SSS conceived and coordinated the study. RP and SSS performed the experiments and analyzed the data. ECS contributed with samples and reagents. SSS drafted the manuscript. All authors read and approved the final manuscript.

\section{Acknowledgements}

This work was supported by grants 2011/11090-5, 2011/12297-2, and 2014/ 24596-2 from the Fundação de Amparo à Pesquisa do Estado de São Paulo.

\section{Author details}

'Department of Pathology, Hospital das Clínicas, School of Medicine, University of São Paulo, São Paulo, Brazil. ${ }^{2}$ Department of Infectious Disease/ Institute of Tropical Medicine, University of São Paulo, Sao Paulo, Brazil. ${ }^{3}$ Medicina Instituto de Medicina Tropical de São Paulo, LIM 52 - Av. Dr. Enéas Carvalho de Aguiar, $470-2^{\circ}$ andar - Cerqueira Cesar, 05403-000 Sao Paulo, SP, Brazil.
Received: 23 March 2015 Accepted: 5 May 2015

Published online: 14 May 2015

\section{References}

1. Berger EA: HIV entry and tropism: the chemokine receptor connection. AIDS. 1997;11(Suppl A):S3-16.

2. Bomsel M, David V. Mucosal gatekeepers: selecting HIV viruses for early infection. Nat Med. 2002;8(2):114-6.

3. Philpott SM. HIV-1 coreceptor usage, transmission, and disease progression. Curr HIV Res. 2003;1 (2):217-27.

4. Casper C, Naver L, Clevestig P, Belfrage E, Leitner T, Albert J, et al. Coreceptor change appears after immune deficiency is established in children infected with different HIV-1 subtypes. AIDS Res Hum Retroviruses. 2002;18(5):343-52.

5. Connor Rl, Sheridan KE, Ceradini D, Choe S, Landau NR. Change in coreceptor use correlates with disease progression in HIV-1-infected individuals. J Exp Med. 1997;185(4):621-8.

6. Scarlatti G, Tresoldi E, Bjorndal A, Fredriksson R, Colognesi C, Deng HK, et al. In vivo evolution of HIV-1 co-receptor usage and sensitivity to chemokinemediated suppression. Nat Med. 1997;3(11):1259-65.

7. Cooper DA, Heera J, Goodrich J, Tawadrous M, Saag M, Dejesus E, et al. Maraviroc versus efavirenz, both in combination with zidovudine-lamivudine, for the treatment of antiretroviral-naive subjects with CCR5-tropic HIV-1 infection. J Infect Dis. 2010;201(6):803-13.

8. Fatkenheuer G, Nelson M, Lazzarin A, Konourina I, Hoepelman Al, Lampiris $\mathrm{H}$, et al. Subgroup analyses of maraviroc in previously treated R5 HIV-1 infection. N Engl J Med. 2008;359(14):1442-55.

9. Whitcomb JM, Huang W, Fransen S, Limoli K, Toma J, Wrin T, et al. Development and characterization of a novel single-cycle recombinant-virus assay to determine human immunodeficiency virus type 1 coreceptor tropism. Antimicrob Agents Chemother. 2007;51(2):566-75.

10. Hwang SS, Boyle TJ, Lyerly HK, Cullen BR. Identification of the envelope V3 loop as the primary determinant of cell tropism in HIV-1. Science. 1991;253(5015):71-4.

11. Lengauer T, Sander O, Sierra S, Thielen A, Kaiser R. Bioinformatics prediction of HIV coreceptor usage. Nat Biotechnol. 2007;25(12):1407-10.

12. Vandekerckhove LP, Wensing AM, Kaiser R, Brun-Vezinet F, Clotet B, De Luca A, et al. European guidelines on the clinical management of HIV-1 tropism testing. Lancet Infect Dis. 2011;11(5):394-407.

13. Gulick RM, Lalezari J, Goodrich J, Clumeck N, DeJesus E, Horban A, et al. Maraviroc for previously treated patients with R5 HIV-1 infection. N Engl J Med. 2008;359(14):1429-41.

14. De Jong JJ, De Ronde A, Keulen W, Tersmette M, Goudsmit J. Minimal requirements for the human immunodeficiency virus type 1 V3 domain to support the syncytium-inducing phenotype: analysis by single amino acid substitution. J Virol. 1992;66(11):6777-80.

15. Fouchier RA, Brouwer M, Broersen SM, Schuitemaker $\mathrm{H}$. Simple determination of human immunodeficiency virus type 1 syncytium-inducing V 3 genotype by PCR. J Clin Microbiol. 1995;33(4):906-11.

16. Swenson LC, Moores A, Low AJ, Thielen A, Dong W, Woods C, et al. Improved detection of CXCR4-using HIV by V3 genotyping: application of population-based and "deep" sequencing to plasma RNA and proviral DNA. J Acquir Immune Defic Syndr. 2010;54(5):506-10.

17. Alencar CS, Nishiya AS, Ferreira S, Giret MT, Diaz RS, Sabino EC. Evaluation of primary resistance to HIV entry inhibitors among brazilian patients failing reverse transcriptase/protease inhibitors treatment reveal high prevalence of maraviroc resistance-related mutations. AIDS Res Hum Retroviruses. 2010;26(12):1267-71.

18. Araujo LA, Junqueira DM, de Medeiros RM, Matte MC, Almeida SE. Naturally occurring resistance mutations to HIV-1 entry inhibitors in subtypes B, C, and CRF31_BC. J Clin Virol. 2012;54(1):6-10.

19. Parisi SG, Andreis S, Mengoli C, Scaggiante R, Ferretto R, Manfrin V, et al. Baseline cellular HIV DNA load predicts HIV DNA decline and residual HIV plasma levels during effective antiretroviral therapy. J Clin Microbiol. 2012;50(2):258-63.

20. Raymond S, Delobel P, Mavigner M, Cazabat M, Encinas S, Souyris C, et al. CXCR4-using viruses in plasma and peripheral blood mononuclear cells during primary HIV-1 infection and impact on disease progression. AIDS. 2010;24(15):2305-12.

21. Verhofstede C, Brudney D, Reynaerts J, Vaira D, Fransen K, De Bel A, et al. Concordance between HIV-1 genotypic coreceptor tropism predictions based on plasma RNA and proviral DNA. HIV Med. 2011;12(9):544-52. 
22. Brown J, Burger H, Weiser B, Pollard RB, Li XD, Clancy LJ, et al. A genotypic HIV-1 proviral DNA coreceptor tropism assay: characterization in viremic subjects. AIDS Res Ther. 2014;11:14.

23. Pessoa R, Watanabe JT, Calabria P, Alencar CS, Loureiro P, Lopes ME, et al.: Enhanced detection of viral diversity using partial and near full-length genomes of human immunodeficiency virus Type 1 provirus deep sequencing data from recently infected donors at four blood centers in Brazil. Transfusion 2014 (e-pub ahead of print, 21 November 2012; doi:10.1111/trf.12936).

24. Sabino EC, Goncalez TT, Carneiro-Proietti AB, Sarr M, Ferreira JE, Sampaio DA, et al. Human immunodeficiency virus prevalence, incidence, and residual risk of transmission by transfusions at Retrovirus Epidemiology Donor Study-II blood centers in Brazil. Transfusion. 2012;52(4):870-9.

25. Swenson LC, Mo T, Dong WW, Zhong X, Woods CK, Jensen MA, et al. Deep sequencing to infer HIV-1 co-receptor usage: application to three clinical trials of maraviroc in treatment-experienced patients. J Infect Dis. 2011;203(2):237-45

26. Hoffman NG, Seillier-Moiseiwitsch F, Ahn J, Walker JM, Swanstrom R. Variability in the human immunodeficiency virus type 1 gp120 Env protein linked to phenotype-associated changes in the V3 loop. J Virol. 2002;76(8):3852-64.

27. Delgado E, Fernandez-Garcia A, Vega Y, Cuevas T, Pinilla M, Garcia V, et al. Evaluation of genotypic tropism prediction tests compared with in vitro co-receptor usage in HIV-1 primary isolates of diverse subtypes. J Antimicrob Chemother. 2012;67(1):25-31.

28. Delobel P, Nugeyre MT, Cazabat M, Pasquier C, Marchou B, Massip P, et al. Population-based sequencing of the $\mathrm{V} 3$ region of env for predicting the coreceptor usage of human immunodeficiency virus type 1 quasispecies. J Clin Microbiol. 2007:45(5):1572-80.

29. Tamura K, Stecher G, Peterson D, Filipski A, Kumar S. MEGA6: Molecular Evolutionary Genetics Analysis version 6.0. Mol Biol Evol. 2013;30(12):2725-9.

30. Pessoa R, Watanabe JT, Calabria P, Felix AC, Loureiro P, Sabino EC, et al. Deep Sequencing of HIV-1 near Full-Length Proviral Genomes Identifies High Rates of BF1 Recombinants Including Two Novel Circulating Recombinant Forms (CRF) 70_BF1 and a Disseminating 71_BF1 among Blood Donors in Pernambuco Brazil. PLoS One. 2014;9(11):e112674.

31. Westby M, Smith-Burchnell C, Mori J, Lewis M, Mosley M, Stockdale M, et al. Reduced maximal inhibition in phenotypic susceptibility assays indicates that viral strains resistant to the CCR5 antagonist maraviroc utilize inhibitor-bound receptor for entry. J Virol. 2007;81(5):2359-71.

32. de Mendoza C, Van Baelen K, Poveda E, Rondelez E, Zahonero N, Stuyver L, et al. Performance of a population-based HIV-1 tropism phenotypic assay and correlation with $\mathrm{V} 3$ genotypic prediction tools in recent HIV-1 seroconverters. J Acquir Immune Defic Syndr. 2008;48(3):241-4.

33. de Mendoza C, Rodriguez C, Garcia F, Eiros JM, Ruiz L, Caballero E, et al. Prevalence of $\times 4$ tropic viruses in patients recently infected with HIV-1 and lack of association with transmission of drug resistance. J Antimicrob Chemother. 2007:59(4):698-704.

34. Frange P, Galimand J, Goujard C, Deveau C, Ghosn J, Rouzioux C, et al. High frequency of $\times 4 / D M$-tropic viruses in PBMC samples from patients with primary HIV-1 subtype-B infection in 1996-2007: the French ANRS CO06 PRIMO Cohort Study. J Antimicrob Chemother. 2009;64(1):135-41.

35. Brumme ZL, Goodrich J, Mayer HB, Brumme CJ, Henrick BM, Wynhoven B, et al. Molecular and clinical epidemiology of CXCR4-using HIV-1 in a large population of antiretroviral-naive individuals. J Infect Dis. 2005;192(3):466-74.

36. Hunt PW, Harrigan PR, Huang W, Bates M, Williamson DW, McCune JM, et al. Prevalence of CXCR4 tropism among antiretroviral-treated HIV-1-infected patients with detectable viremia. J Infect Dis. 2006;194(7):926-30

37. Soulie C, Fourati S, Lambert-Niclot S, Malet I, Wirden M, Tubiana R, et al. Factors associated with proviral DNA HIV-1 tropism in antiretroviral therapy-treated patients with fully suppressed plasma HIV viral load: implications for the clinical use of CCR5 antagonists. J Antimicrob Chemother 2010;65(4):749-51.

38. Seclen E, Del Mar GM, De Mendoza C, Soriano V, Poveda E. Dynamics of HIV tropism under suppressive antiretroviral therapy: implications for tropism testing in subjects with undetectable viraemia. J Antimicrob Chemother. 2010;65(7):1493-6.

39. Charpentier C, Joly V, Larrouy L, Fagard C, Visseaux B, de Verdiere NC, et al. Role and evolution of viral tropism in patients with advanced HIV disease receiving intensified initial regimen in the ANRS 130 APOLLO trial. J Antimicrob Chemother. 2013;68(3):690-6.
40. Eshleman SH, Husnik M, Hudelson S, Donnell D, Huang Y, Huang W, et al. Antiretroviral drug resistance, HIV-1 tropism, and HIV-1 subtype among men who have sex with men with recent HIV-1 infection. AIDS. 2007;21(9):1165-74

41. Sanabani SS, Pastena ER, da Costa AC, Martinez VP, Kleine-Neto W, de Oliveira $A C$, et al. Characterization of partial and near full-length genomes of HIV-1 strains sampled from recently infected individuals in Sao Paulo Brazil. PLoS One. 2011;6(10):e25869.

42. Bunnik EM, Swenson LC, Edo-Matas D, Huang W, Dong W, Frantzell A, et al. Detection of inferred CCR5- and CXCR4-using HIV-1 variants and evolutionary intermediates using ultra-deep pyrosequencing. PLoS Pathog. 2011;7(6):e1002106.

43. Bansode V, McCormack GP, Crampin AC, Ngwira B, Shrestha RK, French N, et al. Characterizing the emergence and persistence of drug resistant mutations in HIV-1 subtype C infections using 454 ultra deep pyrosequencing. BMC Infect Dis. 2013;13:52

44. Grivel JC, Shattock RJ, Margolis LB. Selective transmission of R5 HIV-1 variants: where is the gatekeeper? J Transl Med. 2011;9 Suppl 1:S6.

45. Chalmet K, Dauwe K, Foquet L, Baatz F, Seguin-Devaux C, Van Der Gucht B, et al. Presence of CXCR4-using HIV-1 in patients with recently diagnosed infection: correlates and evidence for transmission. J Infect Dis. 2012;205(2):174-84.

46. Frange $P$, Meyer $L$, Jung M, Goujard C, Zucman D, Abel S, et al. Sexuallytransmitted/founder HIV-1 cannot be directly predicted from plasma or PBMC-derived viral quasispecies in the transmitting partner. PLoS One. 2013;8(7):e69144.

47. Skrabal K, Low AJ, Dong W, Sing T, Cheung PK, Mammano F, et al. Determining human immunodeficiency virus coreceptor use in a clinical setting: degree of correlation between two phenotypic assays and a bioinformatic model. J Clin Microbiol. 2007;45(2):279-84.

48. McGovern RA, Thielen A, Mo T, Dong W, Woods CK, Chapman D, et al. Population-based V3 genotypic tropism assay: a retrospective analysis using screening samples from the A4001029 and MOTIVATE studies. AIDS. 2010;24(16):2517-25

49. Chueca N, Garrido C, Alvarez M, Poveda E, de Dios LJ, Zahonero N, et al. Improvement in the determination of HIV-1 tropism using the $\mathrm{V} 3$ gene sequence and a combination of bioinformatic tools. J Med Virol. 2009;81(5):763-7.

50. Raymond S, Delobel P, Mavigner M, Cazabat M, Souyris C, Sandres-Saune K, et al. Correlation between genotypic predictions based on V3 sequences and phenotypic determination of HIV-1 tropism. AIDS. 2008;22(14):F11-6.

\section{Submit your next manuscript to BioMed Central and take full advantage of:}

- Convenient online submission

- Thorough peer review

- No space constraints or color figure charges

- Immediate publication on acceptance

- Inclusion in PubMed, CAS, Scopus and Google Scholar

- Research which is freely available for redistribution 